\title{
Oscillatory Correlates of Retrieval-induced Forgetting in Recognition Memory
}

\author{
Bernhard Spitzer ${ }^{1}$, Simon Hanslmayr ${ }^{1}$, Bertram Opitz ${ }^{2}$, \\ Axel Mecklinger ${ }^{2}$, and Karl-Heinz Bäuml ${ }^{1}$
}

\begin{abstract}
Retrieval practice on a subset of previously studied material enhances later memory for practiced material but can inhibit memory for related unpracticed material. The present study examines the effects of prior retrieval practice on evoked (ERPs) and induced (oscillatory power) measures of electrophysiological activity underlying recognition of practiced and unpracticed words. Compared to control material, recognition of unpracticed words was characterized by reduced amplitudes of the P2 ERP component and by reduced early (200-400 msec) oscillatory theta power. The reduction in P2 amplitude was associated with decreased evoked theta power but not with decreased theta phase locking (phase-
\end{abstract}

\section{INTRODUCTION}

Retrieving a subset of previously studied material can cause subsequent forgetting of related nonretrieved material. This type of forgetting has been extensively investigated using the retrieval-practice paradigm (Anderson, Bjork, \& Bjork, 1994; for a review, see Anderson, 2003). In this paradigm, subjects study items from different semantic categories (e.g., Fruit-Orange, Fruit-Apple, InsectBee). Then, in a subsequent retrieval-practice phase, they are asked to retrieve half of the items from half of the studied categories using the items' word stems as retrieval cues (e.g., Fruit-Or_). Finally, following a distractor task, memory performance for all initially studied items is tested. The typical result in this experiment is that, relative to the control items from the unpracticed categories (Bee), memory for the practiced material (Orange) is improved, but memory for the related unpracticed material from practiced categories (Apple) is impaired.

\section{Retrieval-induced Forgetting and Inhibition}

It is often assumed that retrieval-induced forgetting is caused by inhibition. The proposal is that during re-

\footnotetext{
${ }^{1}$ Regensburg University, Germany, ${ }^{2}$ Saarland University, Germany
}

locking index). Recognition of unpracticed material was further accompanied by a reduction in occipital gamma power (>250 $\mathrm{msec}$ ). In contrast, the beneficial effects of retrieval practice on practiced words were reflected by larger parietal ERP positivity (>500 $\mathrm{msec})$ and by a stronger decrease in oscillatory alpha power in a relatively late time window (>700 msec). The results suggest that the beneficial and detrimental effects of retrieval practice are mediated by different processes. In particular, they suggest that reduced theta (4$7 \mathrm{~Hz})$ and gamma $(60-90 \mathrm{~Hz})$ power reflect the specific effects of inhibitory processes on the unpracticed material's memory representation.

trieval practice on a subset of studied material, related unpracticed items interfere. To reduce this interference, the unpracticed material is inhibited, leading to persistent deactivation of the unpracticed items' memory representation (for reviews, see Bäuml, 2008, or Anderson, 2003; for noninhibitory accounts, see Perfect et al., 2004, or Williams \& Zacks, 2001). Consistent with this hypothesis, retrieval-induced forgetting has been shown to be a retrieval-specific effect (Bäuml, 2002; Anderson, Bjork, \& Bjork, 2000; Ciranni \& Shimamura, 1999) and to be present over a wide range of memory tests, including recognition tests (e.g., Spitzer \& Bäuml, 2007; Hicks \& Starns, 2004), so-called independent-probe tests (e.g., Aslan, Bäuml, \& Pastötter, 2007; Anderson \& Spellman, 1995; but see Camp, Pecher, \& Schmidt, 2007), and some implicit tests (e.g., Bajo, Gómez-Ariza, Fernandez, \& Marful, 2006; Veling \& Van Knippenberg, 2004). According to the inhibitory account of retrieval-induced forgetting, inhibition leads to deactivation of the unpracticed items' inherent memory representation rather than disrupting the items' associative retrieval routes (see also Bäuml, Zellner, \& Vilimek, 2005). In accordance with such a proposal, a recent analysis of remember/ know data and receiver operating characteristics (ROCs) showed that, in item recognition, retrieval practice mainly affects the unpracticed material's memory strength (i.e., familiarity) and influences the material's episodic recollection to a much lesser extent (Spitzer \& Bäuml, 2007). 
Recently, Johansson, Aslan, Bäuml, Gäbel, and Mecklinger (2007) investigated possible electrophysiological correlates of the inhibitory mechanisms underlying retrieval-induced forgetting. Early onsetting and sustained prefrontal ERP positivity during retrieval practice was related to whether or not retrieval was required during reprocessing of the studied material. In particular, the ERP positivity was predictive of individual differences in the amount of retrievalinduced forgetting. Consistently, in a recent fMRI study (Kuhl, Dudukovic, Kahn, \& Wagner, 2007), subsequent forgetting of competing memories was associated with a decline in demands on prefrontal structures in the course of retrieval practice, particularly involving the anterior cingulate cortex and the right lateral prefrontal cortex. Thus, prefrontal regions appear to be critically involved when the inhibitory processes which mediate retrievalinduced forgetting operate (for related evidence, see Anderson et al., 2004, and Wimber, Rutschmann, Greenlee, \& Bäuml, 2008). To date, however, it is largely unclear which neurophysiological processes reflect the persistent effects of such inhibitory function on the affected memory representations.

\section{ERP Correlates of Recognition Memory}

Recognition memory tasks are a useful means to investigate the electrophysiological mechanisms underlying the assessment and evaluation of memory representations. In human scalp EEG, recognition of formerly studied material is typically characterized by the well-known ERP old/new effect which refers to the observation that correct recognition of old (i.e., formerly studied) items elicits different ERP waveforms at frontal and parietal recording sites compared to correct rejection of new (i.e., unstudied) items (e.g., Rugg et al., 1998; Rugg \& Doyle, 1992). More specifically, mid-frontal old/new effects in the time window of the FN400 component (approx. 300-500 msec) have been associated with stimulus familiarity, whereas later (approx. 500-800 msec) left parietal old/new effects (late parietal positivity [LPP]) are assumed to index recollection of spatio-temporal information associated with the prior occurrence of the presented stimulus (e.g., Curran, Tepe, \& Piatt, 2006; Jäger, Mecklinger, \& Kipp, 2006; Woodruff, Hayama, \& Rugg, 2006; Rugg \& Yonelinas, 2003; Mecklinger, 2000; for alternative theoretical accounts of ERP old/new effects, see Voss \& Paller, 2006; Yovel \& Paller, 2004). In addition to these well-known recognition correlates, frontally distributed ERP old/new effects have also been reported in the time window of the P2 component (approx. 150-300 msec; e.g., Curran \& Dien, 2003; Tsivilis, Otten, \& Rugg, 2001; Curran, 1999). Such early ERP old/new effects have been vaguely associated with perceptual priming mechanisms (e.g., Curran \& Dien, 2003), but their precise functional significance remains unclear to date.

A majority of studies investigating the electrophysiological correlates of recognition memory have relied on the analysis of evoked EEG activity, which is phase locked with respect to stimulus onset (i.e., ERPs). A growing body of literature suggests that ERPs are significantly modulated-or even generated-by low-frequency oscillatory brain activity (e.g., Hanslmayr et al., 2007; Fell et al., 2004; Makeig et al., 2002). Critically, ERP waveforms can theoretically be influenced by either modulations in phase locking or, with sufficiently strong phase locking, modulations in oscillatory power within specified frequency ranges. Thus, the detailed analysis of oscillatory activity may allow for differentiating EEG effects that appear indistinguishable in the ERP. Consistently, Roehm, Schlesewsky, Bornkessel, Frisch, and Haider (2004) recently showed that two similar ERP waveforms may differ with respect to phase locking and power; they found the ERP of one experimental condition to be accompanied by large power and weak phase locking, and found the ERP of the other experimental condition to be accompanied by low power and large phase locking.

\section{Oscillatory Correlates of Recognition Memory}

In recognition tests, the repeated presentation of priorily studied material typically elicits a pronounced power increase in the theta frequency range $(4-7 \mathrm{~Hz})$ starting approximately $200 \mathrm{msec}$ after stimulus onset. The degree of such an increase in theta power has been related to the strength of the episodic memory traces processed during recognition (Klimesch et al., 2006). It has further been suggested that the time course of such theta power increases may be functionally related to the memory processes underlying mid-frontal and parietal ERP old/ new effects (i.e., familiarity and recollection; Klimesch et al., 2001). However, the precise functional relation between ERP old/new effects and oscillatory theta old/ new effects remains to be investigated. With respect to the early onset of theta power increases after presentation of formerly studied items (approx. $200 \mathrm{msec}$ ), it may alternatively be hypothesized that the increase in theta power is related to earlier ERP components, such as P2 (or N2), rather than to FN400 or late parietal positivity.

Besides the oscillatory recognition correlates in the theta frequency range (e.g., Jacobs, Hwang, Curran, \& Kahana, 2006; Kahana, 2006; Klimesch et al., 2001, 2006), it has been suggested that gamma oscillations (30-100 Hz) may play a role in recognition tasks as well (e.g., Herrmann, Munk, \& Engel, 2004; Düzel et al., 2003). Consistently, it has been shown that increases in induced gamma activity are associated with successful encoding and recognition of the study material (e.g., Osipova et al., 2006; Gruber, Tsivilis, Montaldi, \& Müller, 2004). Such induced gamma activity has been linked to feature binding processes, that is, processes that integrate diverse sensory information into a coherent representation of a single object or item (e.g., TallonBaudry \& Bertrand, 1999). In accordance with this proposal, memory-related modulations in induced gamma 
activity during recognition have been associated with the reactivation of representations established during encoding (Gruber et al., 2004). Such gamma activity may thus in particular reflect the sensory aspects of an item's memory representation.

Oscillations in the alpha band $(8-13 \mathrm{~Hz})$ have been associated with memory processes as well (for a review, see Klimesch, Sauseng, \& Hanslmayr, 2007). For instance, alpha oscillations have been linked to complex spreading activation processes in long-term memory (e.g., Klimesch et al., 2007; Klimesch, Schimke, \& Schwaiger, 1994) and may thus also be involved in episodic recognition. Consistently, Burgess and Gruzelier (2000) reported relatively late repetition effects in the alpha frequency range during recognition of words and faces. Therefore, in the present study, we focused on theta, gamma, and alpha frequencies when examining oscillatory brain activity in episodic recognition.

\section{Goal of the Present Study}

The present study aims to investigate the effects of prior retrieval practice on oscillatory brain activity $(4-100 \mathrm{~Hz})$ and ERP measures during recognition of formerly studied material. The standard retrieval-practice paradigm (Anderson et al., 1994) was employed. Subjects studied semantically categorized word lists and subsequently performed retrieval practice on a subset of the material. Finally, an item recognition test was applied in which the practiced, unpracticed, and control material (in addition to lures) were presented. During this test, scalp EEG was recorded. Based on prior work (e.g., Spitzer \& Bäuml, 2007; Hicks \& Starns, 2004), we expected improved recognition of practiced material as well as impaired recognition of unpracticed material relative to control items from unpracticed categories, which is consistent with the assumption that the inhibitory processes operating during retrieval practice deactivate the unpracticed items' memory representation. The EEG analysis focused on identifying the electrophysiological signature of such inhibitory deactivation.

Given prior demonstrations that retrieval-induced forgetting can affect stimulus familiarity (Spitzer \& Bäuml, 2007) as well as performance in implicit memory tests (e.g., Bajo et al., 2006; Veling \& Van Knippenberg, 2004), we expected that the detrimental effects of retrieval practice on the unpracticed material may already be evident relative early in EEG measures, that is, in terms of a reduction in early ERP old/new effects ( $<500 \mathrm{msec})$. Further, if the inhibitory mechanisms underlying retrieval-induced forgetting lead to a weakening of the unpracticed items' memory representation, such weakening may be evident in reduced oscillatory activity in the theta frequency range, assuming that such theta activity reflects the strength of an item's memory trace (e.g., Klimesch et al., 2001, 2006). In addition, inhibitory deactivation of unpracticed material may also entail a weakening of the material's sensory representation, which might be reflected in a reduction in memoryrelated activity in the gamma frequency range (e.g., Osipova et al., 2006).

Regarding the beneficial effects of retrieval practice on recognition of practiced material, we hypothesized that the repeated processing of the material in different phases of the experiment may enrich contextual (i.e., recollective) information associated with the material. We therefore expected the facilitation of practiced material to be reflected in relative late EEG correlates of recognition memory (>500 $\mathrm{msec}$ ), which are assumed to index conscious recollection of spatio-temporal context information (e.g., Rugg \& Yonelinas, 2003). On balance, we speculated that the particular neural signature of inhibitory forgetting may be qualitatively distinct from possible correlates of the expected facilitation of the practiced material.

\section{METHODS}

\section{Participants}

Subjects were 30 adults (19-34 years old, 16 women, 14 men) who participated voluntarily in the experiment. They were tested individually in two subsequent sessions, each lasting approximately $30 \mathrm{~min}$. Two subjects were excluded from the data analysis due to excessive eye movement artifact.

\section{Materials}

In each of the two sessions, stimuli were 12 concrete German words from each of nine semantic categories (Mannhaupt, 1983; Battig \& Montague, 1969). In Session 1, the categories were body part, sport, musical instrument, quadruped, piece of furniture, tool kit, spice, tree, and car part. In Session 2, the categories were alcoholic drink, fruit, organ, bird, disease, article of clotbing, African state, planet, and profession. It was assured that none of the chosen category exemplars was directly associated with any of the members of the other categories used in the experiment. Within each category, the chosen exemplars were 12 relatively strong exemplars (rank 4-15 in the norms). Six of the chosen exemplars (rank 7-12) were used in the study phase of the experiment, and the remaining six exemplars (rank 4-6 and 13-15) were used as lures in the recognition memory test (see also Spitzer \& Bäuml, 2007, or Hicks \& Starns, 2004). Additionally, four exemplars from each of the three categories, bygiene, sweets, and stationery, were used as buffer items in Session 1, and four exemplars from each of the three categories, media, pasta, and geometric shapes, were used as buffer items in Session 2, for a total of 12 buffer items in each session. 


\section{Design}

The experiment consisted of two separate sessions which differed only in material. Each session consisted of three main phases: a study phase, a retrieval-practice phase, and a final test phase. In the study phase, $54(9 \times 6)$ category exemplars were presented for study. In the retrieval-practice phase, subjects practiced three exemplars from each of six of the nine studied categories. Thus, in each session, $18(6 \times 3)$ items were practiced, $18(6 \times 3)$ items from practiced categories were unpracticed, and $18(3 \times 6)$ items from the remaining three categories served as controls. The practiced items are referred to as $\mathrm{P}+$ items in the following, the unpracticed items from the practiced categories as $\mathrm{P}$ - items, and the control items from the unpracticed categories as $\mathrm{C}$ items. In the final test phase, the 54 study items as well as 54 $(9 \times 6)$ lures from the nine studied categories were used for a test of item recognition.

\section{Procedure}

Subjects were tested individually in a quiet surrounding, seated in front of a 15-in. computer screen. At the beginning of the study phase, an instruction to memorize all to-be-presented words was displayed. Then, each item was presented for $2000 \mathrm{msec}$ without its category cue, followed by a 500-msec blank screen. Throughout the experiment, all items were displayed in the middle of the screen in a white Arial font (boldface 20 pt.) against a black background. The order of the items was block randomized (i.e., a random sequence of six blocks consisting of one randomly selected exemplar from each of the nine categories was presented to the participants with the constraint that no item in the sequence shared the next exemplar's category). Additionally, four buffer items were shown at the beginning of the study list, and four buffer items were shown at the end. After the study phase, subjects were instructed to count backward from 500 in steps of threes for 60 sec. Subsequently, the retrieval-practice phase started in which subjects practiced $18(6 \times 3)$ of the studied items. For each tobe-practiced item, a category/word-stem pair was presented on the screen (e.g., FRUIT-Ap...) and subjects were asked to complete the word stem with a studied item. The experimenter noted the subject's response on a prepared data sheet and participants proceeded to the next item by pressing a key. The order of the category/ word-stem pairs was block randomized. After presentation of the 18 to-be-practiced items, the procedure was identically repeated, leading to two retrieval practice trials for each single item. For the following $5 \mathrm{~min}$, subjects worked on simple arithmetic problems as a distractor task. In the final test phase, a recognition test was conducted. Each trial consisted of a 350-msec blank screen which was followed by a random interval (1500$2000 \mathrm{msec}$ ) fixation cross. Subjects were instructed to fixate the cross and to prepare for the presentation of a test item, avoiding eye movements or blinks. Then the test item was presented for 1200 msec, followed by a 500-msec blank screen. Subsequently, the question "new (n) or old (o)?" was displayed and subjects were instructed to enter their response via specified keys on the PC keyboard. Subjects were given a maximum time of $10 \mathrm{sec}$ for their response (no response feedback was given). The order of the test items (targets and lures) was block randomized with the additional constraint that none of the item types $(\mathrm{P}+, \mathrm{P}-, \mathrm{C}$, new) appeared more than four times in a row. After completion of the first session and a break of about $10 \mathrm{~min}$, the procedure was repeated with the second set of item material.

\section{EEG Recording and Analysis}

During the recognition test phase, EEG activity was recorded continuously from 63 mostly equidistant Ag/ $\mathrm{AgCl}$ electrodes mounted on a preconfigured elastic cap (BrainCap64, Easycap) according to the extended 10-20 system. Signals between 0.3 and $250 \mathrm{~Hz}$ were recorded and digitized at a sample rate of $500 \mathrm{~Hz}$ using Brain Amp MR plus (Brain Products, Munich; all impedances were kept below $5 \mathrm{k} \Omega$ ). Recordings were initially referenced to $\mathrm{FCz}$, then converted to an average reference off-line. The EEG data were corrected for eye movements using calibration data to generate individual artifact coefficients and the algorithm was implemented in the software package BESA (MEGIS Software BESA v5.1.8; see Ille, Berg, \& Scherg, 2002 for details). Remaining artifacts were excluded from analysis by visual inspection, on average, discarding 16.8\% (P+ hits), 18.9\% ( $\mathrm{P}-$ hits), 18.0\% (C hits), and 18.6\% (correct rejections) of the critical trials. We thus ended up with an average of 28.6 (23-33) P+ hits, 22.4 (16-29) P- hits, 24.8 (19-30) $\mathrm{C}$ hits, and 76.0 (53-101) correct rejections of new items for EEG analysis. EEG analyses focused on three contrasts of interest: Old/new effects were assessed by contrasting correctly recognized control items (C) with correctly rejected new items; Correlates of retrievalinduced forgetting were assessed by contrasting hits to control items (C) with hits to unpracticed items $(\mathrm{P}-)$; finally, correlates of the expected facilitation of practiced material were assessed by contrasting hits to practiced items $(\mathrm{P}+)$ with hits to control items (C).

\section{ERP Analysis}

ERPs were computed separately for each subject and item type with epochs extending from $200 \mathrm{msec}$ before stimulus onset until $1200 \mathrm{msec}$ thereafter. The ERPs were analyzed for six regions of interest (ROIs) and for two time windows, inferred from recognition memory literature reporting early (<500 $\mathrm{msec}$ ) ERP old/new effects at frontal recording sites (mid-frontal old/new 
effects) and late (>500 msec) ERP old/new effects at parietal recording sites (parietal old/new effects; e.g., Rugg \& Yonelinas, 2003). The ROIs were left-frontal (LF): F7, F5, F3, FC5, FC3; mid-frontal (MF): F1, Fz, F2, FC1, FCz, FC2; right-frontal (RF): F4, F6, F8, FC4, FC6; left-parietal (LP): CP5, CP3, P7, P5, P3; mid-parietal (MP): CP1, CPz, CP2, P1, Pz, P2; right-parietal (RP): CP4, CP6, $\mathrm{P} 4, \mathrm{P} 6, \mathrm{P} 8$. The time windows were 300-500 msec (FN400) and 500-750 msec (LPP). For analysis of P2 old/new effects, the mean latencies and peak amplitudes of the frontal P2 component were determined for each subject, item type, and ROI (LF, MF, RF) within a time interval of 150-300 msec after stimulus onset using the semiautomatic peak detection algorithm implemented in Brain Vision Analyzer Software (Brain Products $\mathrm{GmbH}$ ). Each automatically detected peak location was carefully checked and manually adjusted where necessary. For analysis of the effects on FN400 and LPP, the mean amplitudes were calculated in the respective time windows. P2, FN400, and LPP effects were analyzed separately, using two-way (Item type $\times$ $\mathrm{ROI})$ repeated measures analyses of variance (ANOVAs). For all reported ANOVAs, the Greenhouse-Geisser correction was used.

\section{Oscillatory Power Analysis}

All time-frequency analyses were carried out using the BESA software package and self-written Matlab codes (The Mathworks Inc.). For analysis of low-frequency oscillatory power, the data were filtered in a frequency range of 4 to $20 \mathrm{~Hz}$ using BESA's time-frequency analysis module, with time-frequency resolution set to $50 \mathrm{msec}$ and $1 \mathrm{~Hz}$. In order to allow for direct comparisons between low-frequency oscillations and the ERP, we examined absolute power (i.e., no baseline correction was used). Frequency bands and time windows exhibiting significant effects (old/new, forgetting, and/or facilitation) were identified on the basis of statistical timefrequency difference plots indicating the $p$ values of paired $t$ tests (two-tailed) for each time-frequency bin. For initial screening, the data were collapsed across all ROIs that have been used for the ERP analysis. To control for multiple comparisons, effects were only submitted to further analysis if more than five horizontally and/or vertically adjacent time-frequency bins showed a significant difference $(p<.05)$. Significant timefrequency clusters were localized using topographic scalp maps for subsequent ROI-specific analysis.

For analysis of oscillatory power in the gamma band, the data were filtered in a frequency range of 50 to $100 \mathrm{~Hz}$, with time-frequency resolution set to $10 \mathrm{msec}$ and $5 \mathrm{~Hz}$. In order to increase the signal-to-noise ratio when examining differences in high-frequency oscillatory power, the ERD/ERS method was used (Pfurtscheller \& Aranibar, 1977). This method examines stimulus-induced power changes by calculating the percentage of power decrease (ERD) or power increase (ERS) in relation to a prestimulus baseline (set to -500 to $0 \mathrm{msec}$ ). Inferred from prior work reporting occipital gamma (60-90 Hz) old/new effects in episodic item recognition (Osipova et al., 2006), event-related gamma power was analyzed for occipital recording sites (PO3, POz, PO4, O1, Oz, O2). The three contrasts of interest were again examined using statistical time-frequency difference plots as well as topographic scalp maps (see above).

\section{PLI and Evoked Power Analysis}

In contrast to power measures, which retain both induced and evoked oscillatory activity, measures of phase-locking index (PLI) and evoked power allow for a separate analysis of evoked oscillatory activity, that is, oscillatory activity that is phase locked with respect to stimulus onset. The PLI is a measure of phase variability across single trials at a certain time point and ranges from 0 , which is maximal phase variability, to 1 , which is perfect phase locking (see Gruber, Klimesch, Sauseng, \& Doppelmayr, 2005 for details). The PLI was calculated using Gabor wavelet analysis with a frequency resolution of $0.25 \mathrm{~Hz}$. For statistical analysis of a possible relation between theta oscillations and the P2 ERP component, the frequency bins were averaged in a frequency range of 4 to $7 \mathrm{~Hz}$ and in a time window ranging from 150 to 300 msec after stimulus presentation. This particular time-frequency window was chosen because phase locking and evoked power were strongest during this timefrequency window (see Figure 4A and B). Evoked power is a time-frequency transformation of the ERP, and thus, gives information about which frequencies contribute to the ERP. For statistical comparisons, evoked power was calculated using the same Gabor wavelet analysis and time-frequency window as for PLI (150-300 msec, 4-7 Hz).

\section{RESULTS}

\section{Behavioral Results}

\section{Retrieval-practice Phase}

In the retrieval-practice phase, on average, participants successfully completed $89.1 \%(S E=0.01)$ of the category/ word-stem pairs.

\section{Recognition Test}

The proportions of hits and false alarms for each item type are given in Table 1 . Whereas false alarm rates for practiced and unpracticed material did not differ significantly from control material $(p s>.10)$, hit rates were significantly higher for practiced items than for control items $[t(27)=8.84, p<.001]$ and significantly lower for unpracticed items than for control items $[t(27)=4.31$, $p<.001]$. Consistently, mean recognition performance 
Table 1. Behavioral Data

\begin{tabular}{lllr}
\hline & Practiced $(P+)$ & Unpracticed $(P-)$ & Control $(C)$ \\
\hline Hit rate & $0.96(S E=0.01)^{*}$ & $0.77(S E=0.01)^{*}$ & $0.84(S E=0.02)$ \\
FA rate & $0.20(S E=0.03)$ & $0.20(S E=0.03)$ & $0.22(S E=0.02)$ \\
Recognition overall & $0.76(S E=0.02)^{*}$ & $0.57(S E=0.03)^{*}$ & $0.62(S E=0.03)$ \\
Recognition high-forgetting group & $0.73(S E=0.04)^{*}$ & $0.52(S E=0.04)^{*}$ & $0.63(S E=0.04)$ \\
Recognition low-forgetting group & $0.79(S E=0.03)^{*}$ & $0.62(S E=0.04)$ & $0.62(S E=0.04)$ \\
\hline
\end{tabular}

Proportions of hits, false alarms (FA), and recognized items. Recognition performance was calculated as hit rate minus FA rate.

Standard errors are given in parentheses. Asterisks indicate significant deviations from control performance $(p<.05)$.

as indexed by hit rates minus false alarm rates was significantly higher for practiced compared to control material $[t(27)=8.94, p<.001]$ and significantly lower for unpracticed compared to control material $[t(27)=3.84$, $p<.01]$. The behavioral recognition data thus replicate the standard pattern of retrieval-induced forgetting $(\mathrm{P}+>\mathrm{C}>\mathrm{P}-)$. No differences in results were observed between the two successive experimental sessions (all ps $>.15)$.

\section{ERP Results}

The grand-average ERP waveforms for each item type $(\mathrm{P}+, \mathrm{C}, \mathrm{P}-$, new) across frontal and parietal ROIs are illustrated in Figure 1A.

\section{P2 Analysis}

The mean latency of the P2 component across frontal recording sites ( $\mathrm{LF}, \mathrm{MF}, \mathrm{RF})$ was $244 \mathrm{msec}(S E=2.51)$. Mean P2 latencies did not vary significantly across item type $(\mathrm{P}+, \mathrm{C}, \mathrm{P}-$, new $)[F(3,81)<1]$. In contrast, across the three frontal ROIs, a significant main effect of item type $(\mathrm{P}+, \mathrm{C}, \mathrm{P}-$, new) on the amplitude of the $\mathrm{P} 2$ was obtained $[F(3,81)=3.44, p<.05]$. An interaction of factor item type with factor ROI proved to be marginally significant $[F(6,162)=1.86, p=.09]$, suggesting a tendency that the modulation in P2 amplitude was most pronounced at mid-frontal recording sites (see Figure 1B); ROI-specific analyses confirmed this trend [LF: $F(3,81)=1.26, p>.25 ; \mathrm{MF}: F(3,81)=4.35, p<.01$; RF: $F(3,81)=2.40, p=.08]$. At mid-frontal recording sites, the P2 amplitude was marginally larger for control items (C) than for new items $[t(27)=2.02, p=.05]$, that is, a tendency for a P2 old/new effect was observed. In particular, unpracticed items $(\mathrm{P}-)$ elicited a significantly smaller mid-frontal P2 amplitude compared to control items $(\mathrm{C})[t(27)=2.40, p<.05]$. For practiced items $(\mathrm{P}+)$, the $\mathrm{P} 2$ amplitude was not reliably increased compared to control items $(\mathrm{C})[t(27)<1]$. No significant effects during the $\mathrm{P} 2$ time window arose at parietal recording sites (all $F_{S}<1$ ).
To verify whether the observed reduction in midfrontal P2 amplitude for unpracticed items was, in fact, attributable to retrieval-induced forgetting, we split the 28 participants into two equal-sized samples (each $n=14$ ), according to whether they showed high or low retrieval-induced forgetting in the behavioral data analysis [high-forgetting group: 10\% forgetting ( $S E=$ $0.01)$; low-forgetting group: $-1 \%$ forgetting $(S E=0.01)$; see Table 1]. A significant reduction in mid-frontal P2 amplitude was observed for the high-forgetting group $[t(13)=2.61, p<.05]$, whereas no reduction in $\mathrm{P} 2$ amplitude arose for the low-forgetting group $[t(13)<1]$ (Figure 1C).

\section{Late Parietal Positivity}

Across parietal ROIs (LP, MP, RP), a significant main effect of item type $(\mathrm{P}+, \mathrm{C}, \mathrm{P}-$, new $)[F(3,81)=11.38$, $p<.001]$ and a significant interaction with factor ROI $[F(6,162)=3.99, p<.01]$ were obtained on amplitude in the late time window (500-750 msec), suggesting that the late parietal effects of item type in tendency were left lateralized (see Figure 1D). This suggestion was confirmed by ROI-specific analyses [LP: $F(3,81)=$ 9.90, $p<.001$; MP: $F(3,81)=10.84, p<.001$; RP: $F(3$, $81)=1.52, p>.20]$. Across the left and mid-parietal ROIs, control items (C) showed a significant old/new effect when contrasted with new items $[F(1,27)=18.73$, $p<.01]$. Moreover, the LPP was significantly larger for practiced $(\mathrm{P}+)$ compared to control items $(\mathrm{C})[F(1$, $27)=6.36, p<.05]$. In contrast, the LPP was about the same for unpracticed $(\mathrm{P}-)$ and control items $(\mathrm{C})[F(1$, $27)<1$ ]. No significant mid-frontal ERP effects were observed in the 300 to $500 \mathrm{msec}$ time range (FN400, all $F$ S $<1)$.

In sum, ERP analysis indicates that recognition of formerly studied words was characterized by a marginally increased amplitude of the frontal P2 component and a pronounced LPP compared to correctly rejected new items. Interestingly, retrieval-induced forgetting was associated with a reduction in the peak amplitude of the $\mathrm{P} 2$ component for unpracticed material $(\mathrm{P}-$ ) compared to control material $(\mathrm{C})$. In contrast, the facilitation of 


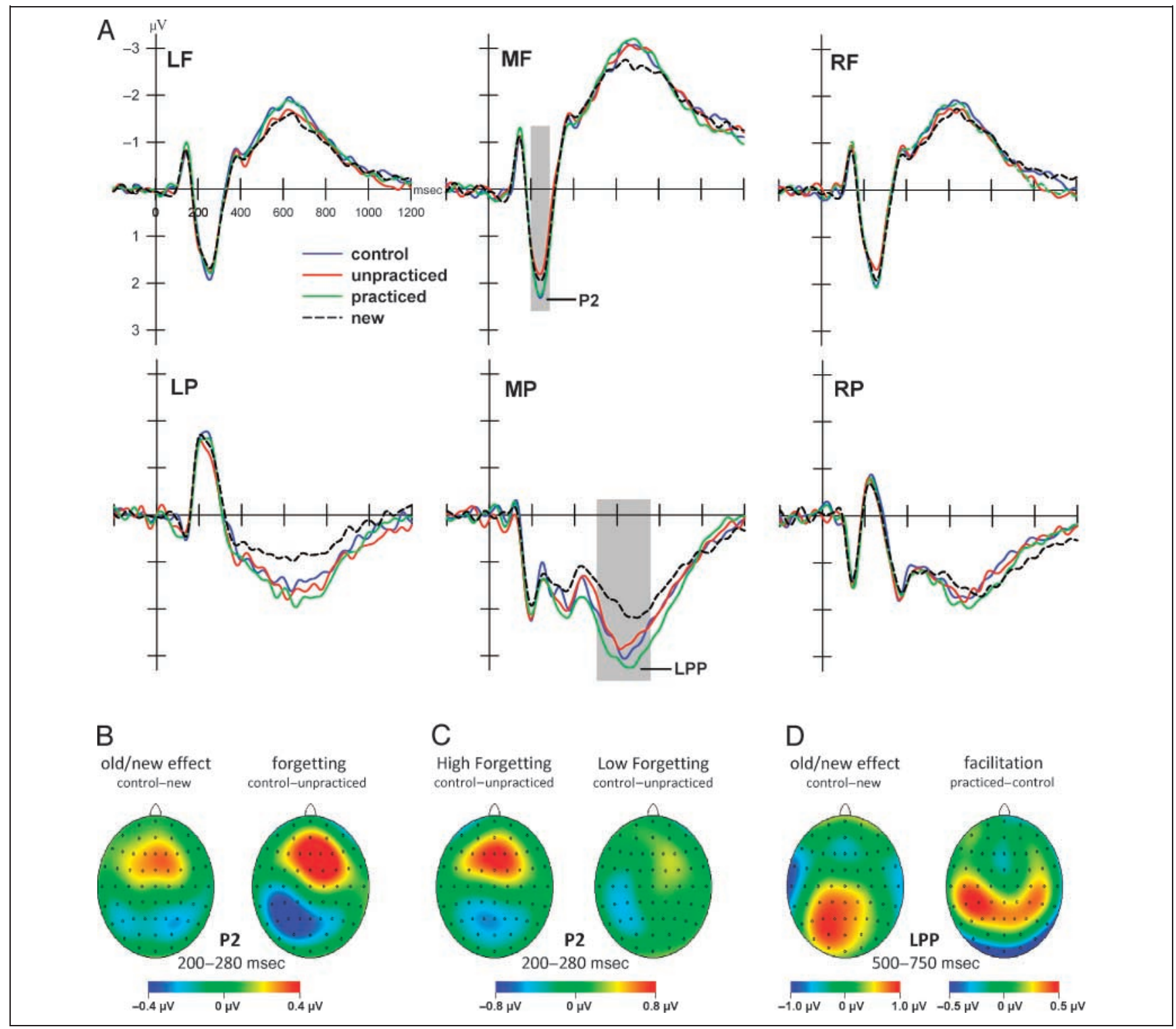

Figure 1. ERP results. (A) Grand-average ERPs for the four item types across frontal and parietal regions of interest ( $L=$ left; $M=$ midline; $\mathrm{R}=$ right; $\mathrm{F}$ = frontal; $\mathrm{P}$ = parietal). Solid blue: Hits to control items from unpracticed categories. Solid red: Hits to unpracticed items from practiced categories. Solid green: Hits to practiced items from practiced categories. Dashed black: Correctly rejected new items. (B) Topographic scalp maps of the effects observed in the time window of the P2 component. (C) Topographic scalp maps of the P2 forgetting effects for subjects showing high retrieval-induced forgetting in the behavioral data analysis (left) and for subjects showing low forgetting (right; see Table 1).

(D) Topographic scalp maps of the effects observed in the time window of the late parietal positivity.

practiced material was reflected by an increased LPP for practiced $(\mathrm{P}+)$ compared to control material (C). ERP analysis thus suggests that forgetting and facilitation in the retrieval-practice paradigm are associated with qualitatively distinct EEG correlates during recognition.

\section{Oscillatory Power}

\section{Theta $(4-7 \mathrm{~Hz})$}

The results from the oscillatory power analysis for the frequency range from 4 to $20 \mathrm{~Hz}$ are illustrated in Figure 2. Inspection of the time-frequency data shows a significant old/new effect in the theta frequency range (4-7 Hz; Figure 2A). This theta old/new effect was characterized by stronger mid-frontal theta power for control items (C) compared to new items and was significant in a time window ranging from 450 to $750 \mathrm{msec}[t(27)=$ $2.26, p<.05]$. Interestingly, recognition of unpracticed items $(\mathrm{P}-)$ was characterized by significantly reduced early theta power compared to control items (C) (Figure $2 \mathrm{~B}$ ). Like the theta old/new effect, this reduction in theta power showed a mid-frontal distribution. At midfrontal recording sites, the reduction was evident from 200 to $850 \mathrm{msec}$, but appeared to be most pronounced in a time window preceding the theta old/new effect 


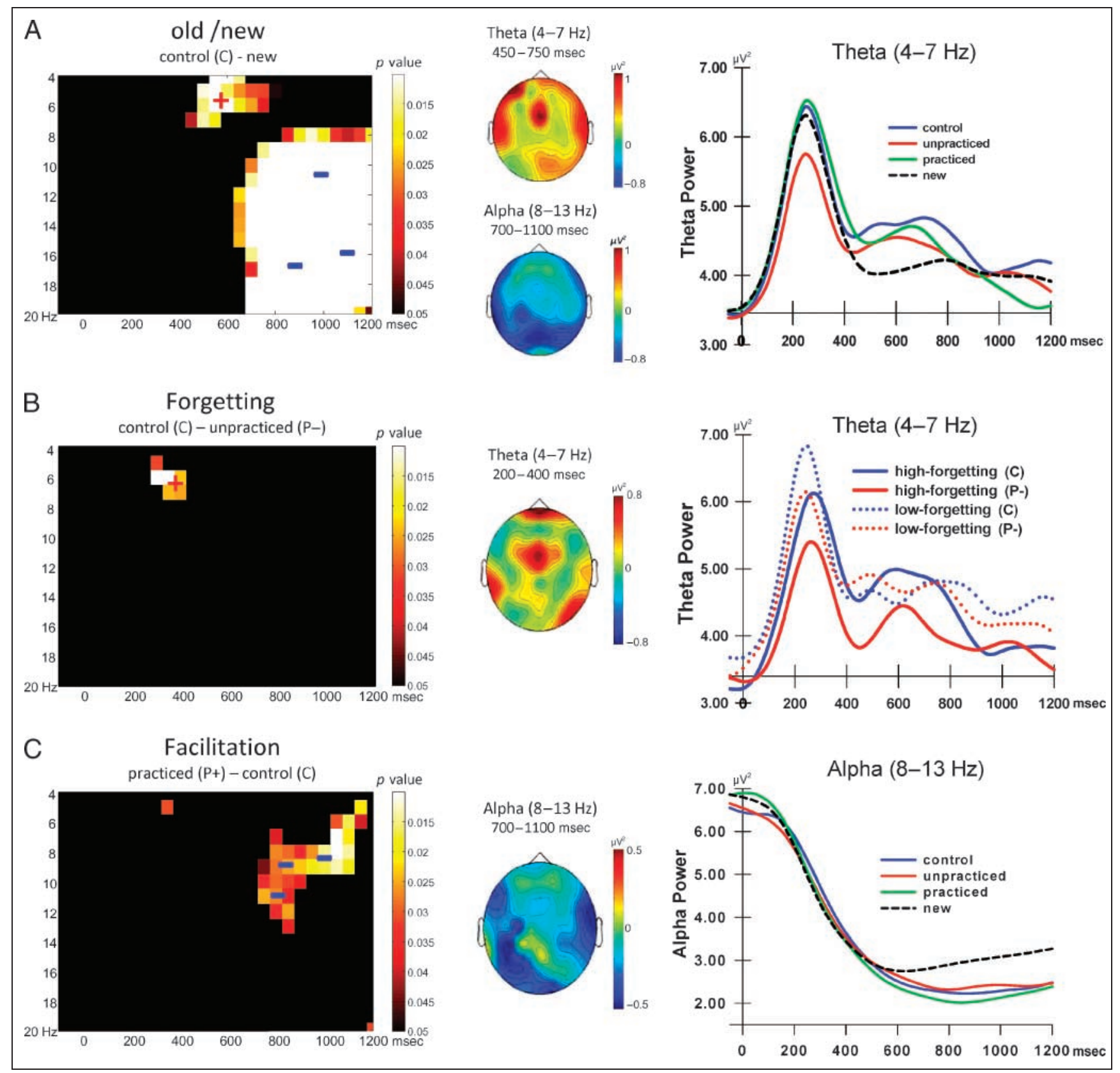

Figure 2. Results from the oscillatory power analysis $(4-20 \mathrm{~Hz}$ ). (A) Left: Time-frequency plot depicting $p$ levels for significant old/new effects. Data are averaged across all electrode sites of interest (ROIs). Red "+ " indicates a stronger power increase; Blue "- " indicates a stronger power decrease. Middle: Topographic scalp maps of significant old/new effects in the theta and alpha frequency band. Right: Mid-frontal theta power for the different item types; line coding analogous to Figure 1A. (B) Left: Time-frequency plot depicting $p$ levels for significant effects of retrieval-induced forgetting (control-unpracticed). Data are averaged across all ROIs. Middle: Topographic scalp map of significant forgetting effects in the theta band. Right: Mid-frontal theta power during recognition of unpracticed (P-) and control items (C) for subjects showing high retrieval-induced forgetting in the behavioral data analysis (solid lines) and for subjects showing low forgetting (dotted lines; see Table 1). (C) Left: Time-frequency plot depicting $p$ levels for significant effects of retrieval-induced facilitation (practiced-control). Data are averaged across all ROIs. Middle: Topographic scalp map of significant facilitation effects in the alpha band. Right: Left parietal alpha power for the different item types; line coding analogous to Figure 1A.

[200-400 msec: $t(27)=3.30, p<.01 ; 450-750 \mathrm{msec}:$ $t(27)=1.67, p=.11]$. Mid-frontal theta power was not increased for practiced $(\mathrm{P}+)$ compared to control items (C) in neither time window [both $t(27)<1$ ].

Analogously to the forgetting-related P2 effects reported above (ERP analysis), we inspected whether the reduction in mid-frontal theta power during recognition of unpracticed material $(\mathrm{P}-)$ was attributable to retrievalinduced forgetting. As illustrated in the right panel of Figure $2 \mathrm{~B}$, subjects in the high-forgetting group showed a strong and persistent reduction in early theta power (200-800 msec), whereas no such reduction was evident 
in the low-forgetting group. A $2 \times 2$ mixed ANOVA with the factors of group (high vs. low forgetting) and item type (C vs. $\mathrm{P}-$ ) revealed a significant effect of item type $[F(1,26)=6.56, p<.05]$, as well as a significant Group $\times$ Item type interaction $[F(1,26)=4.48, p<.05]$. No significant main effect of factor group arose $[F(1,26)<$ 1]. Pairwise comparisons confirmed a significant reduction in theta power for the high-forgetting group $[t(13)=$ 3.06, $p<.01$ ], but not for the low-forgetting group $[t(13)<1]$. These results indicate that reduced theta power may indeed index the detrimental effects of prior retrieval practice on the unpracticed material's memory representation.

\section{Alpha and Beta $(8-20 \mathrm{~Hz})$}

Significant old/new effects were further observed in the alpha and beta frequency range (8-20 Hz, Figure 2A). These topographically widespread old/new effects were characterized by a stronger power decrease for control items (C) compared to new items in a relatively late time window (>700 msec). In the alpha frequency range (8$13 \mathrm{~Hz}$ ), the late power decrease was maximal across parietal recording sites and pronounced from 700 to $1100 \mathrm{msec}[t(27)=2.79, p<.01]$. The alpha power decrease was significantly stronger for practiced $(\mathrm{P}+)$ compared to control (C) material, particularly at left parietal recording sites [700-1100 msec: $t(27)=2.29$, $p<.05$ ] (Figure 2C). No difference was obtained between control $(\mathrm{C})$ and unpracticed material $(\mathrm{P}-)[t(27)=1.10$, $p>$.20]. Exploratory analysis of oscillatory power in the frequency range from 20 to $50 \mathrm{~Hz}$ yielded no reliable effects of retrieval status $(\mathrm{P}+, \mathrm{P}-, \mathrm{C}){ }^{1}$

\section{Gamma (>50 Hz)}

The results from oscillatory gamma power analysis are illustrated in Figure 3. An increase in occipital gamma power (60-85 Hz) was obtained across all four conditions (Figure 3A). Replicating recent work (Osipova et al., 2006), recognition of formerly studied control material (C) was characterized by significantly stronger occipital gamma power (60-85 Hz) compared to correct rejections of new items in a time window ranging from 250 to $1000 \mathrm{msec}$ after stimulus onset $[t(27)=4.74, p<$ $.001]$. Notably, occipital gamma power was significantly

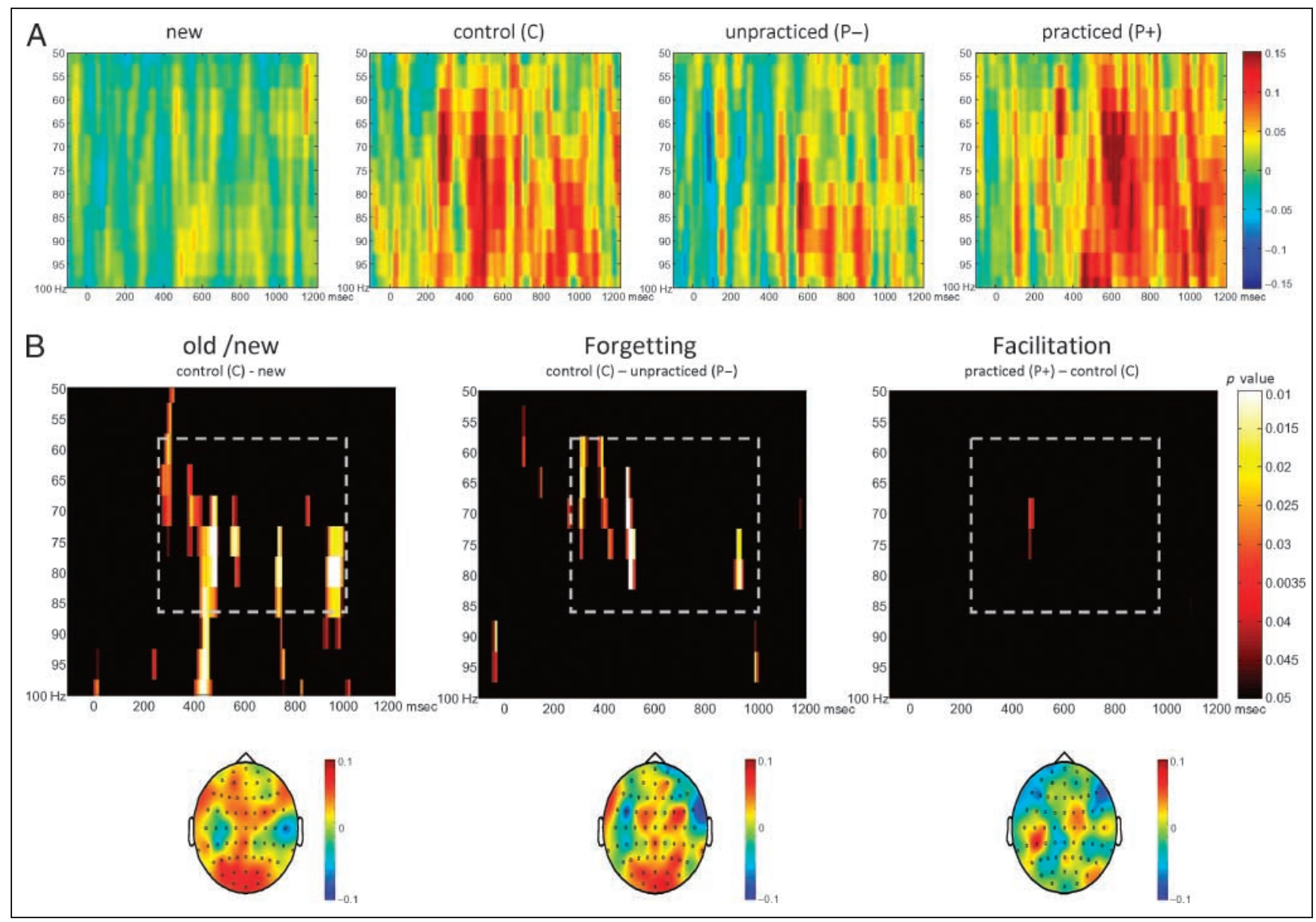

Figure 3. Results from the oscillatory gamma power analysis $(50-100 \mathrm{~Hz})$. (A) Time-frequency plots of occipital gamma power for the four item types. (B) Time-frequency plots depicting $p$ values for the three contrasts of interest, with topographic scalp maps for the selected time-frequency window $(60-85 \mathrm{~Hz}, 250-1000 \mathrm{msec})$. 
reduced during recognition of unpracticed material $(\mathrm{P}-)[t(27)=2.94, p<.01]$, but was not increased for practiced material $(\mathrm{P}+)$ compared to control material $(\mathrm{C})[t(27)<1]$ (Figure $3 \mathrm{~B}$ ).

In sum, recognition of formerly studied control material (C) was characterized by a stronger power increase in the theta and gamma frequency ranges as well as by a stronger subsequent power decrease in the alpha and beta frequency ranges compared to correctly rejected new items. Retrieval-induced forgetting of unpracticed material $(\mathrm{P}-)$ was associated with a reduction in theta and gamma power. Notably, the early reduction in theta power was topographically and temporally similar to the forgetting-related reduction in P2 amplitude reported above. In contrast, facilitation of practiced material $(\mathrm{P}+)$ was reflected by an increased late old/new effect in the alpha frequency range compared to control material (C). These results suggest that forgetting and facilitation in the retrieval-practice paradigm are associated with qualitatively different oscillatory EEG signatures.

\section{PLI and Evoked Power (4-20 Hz)}

Given the notable parallels between the forgettingrelated reductions in $\mathrm{P} 2$ amplitude (ERP analysis) and theta power (oscillatory power analysis), we investigated to what extent early theta oscillations might have contributed to the ERP P2 effects reported above. As can be seen from Figure 4A, recognition of control items (C) was associated with a pronounced increase in both midfrontal phase locking (PLI) and evoked power in the theta frequency range $(4-7 \mathrm{~Hz})$ during the time window of the ERP P2 component ( $200 \mathrm{msec}$ ), suggesting that the ERP P2 component was generated by phase-locked theta oscillations. As illustrated in Figure $4 \mathrm{~B}$ and $\mathrm{C}$, evoked theta power, but not theta phase locking, was significantly reduced for unpracticed material $(\mathrm{P}-)$ compared to control material (C) [evoked power: $t(27)=$ 2.32, $p<.05$; PLI: $t(27)<1$ ], indicating that the reduction in P2 amplitude was indeed modulated by decreased theta power, but was not modulated by reduced intertrial theta phase locking. No significant effects of PLI or evoked power were obtained for higher frequencies $(>7 \mathrm{~Hz})$ and/or later time windows (>400 $\mathrm{msec}$, $p>.05)$.

\section{DISCUSSION}

It has been suggested on the basis of behavioral data that the detrimental effects of retrieval practice may be best characterized as inhibitory deactivation of the unpracticed material's memory representation (see Anderson, 2003). Consistently, retrieval-induced forgetting has been demonstrated over a wide range of memory tests, including recognition testing (e.g., Spitzer \& Bäuml, 2007; Hicks \& Starns, 2004). The present behavioral results replicate this prior work by showing reduced recognition of unpracticed material. Going beyond the prior work, the present EEG results indicate that recognition of unpracticed material is characterized by reduced oscillatory activity in the theta and gamma frequency ranges.

\section{Oscillatory Effects of Retrieval Practice}

\section{Effects on Theta Power}

The results from prior recognition studies suggest a relationship between event-related theta power and the strength of a to-be-recognized item's episodic memory representation (Klimesch et al., 2001, 2006). Finding reduced theta power for unpracticed compared to control material, the present results thus indicate that retrieval practice reduced the memory representation of unpracticed items, a finding which agrees with the inhibitory view of retrieval-induced forgetting (Anderson, 2003). Notably, the reduction in theta power was most pronounced in a time window (200-400 msec after stimulus onset) which preceded the theta old/new effect. That is, the effects of prior retrieval practice on the unpracticed material's representation were already evident at an early processing stage in which oscillatory theta power did not yet discriminate between words presented first (new) and words presented twice $(\mathrm{C})$ or triply $(\mathrm{P}+)$. Although true on average, an analysis of theta power for the high-forgetting group showed that, if forgetting is present, the reduction in theta power is not only quantitatively pronounced but also temporally prolonged, largely overlapping with the time interval of the theta $\mathrm{old} /$ new effect. These results indicate that reductions in theta power during relatively early stages of the recognition test can be accompanied by forgetting in recognition memory. In particular, they suggest that reduced theta power may reflect the specific effects of inhibition on the material's episodic memory representation.

\section{Effects on Gamma Power}

Besides the frontally distributed correlates of retrievalinduced forgetting in the theta frequency range, the analysis of high-frequency oscillatory activity revealed that recognition of unpracticed material was further accompanied by reduced activity in the gamma frequency range $(60-85 \mathrm{~Hz})$. To date, only few long-term memory studies have reported recognition old/new effects in the gamma frequency range (e.g., Osipova et al., 2006; Gruber et al., 2004; Düzel et al., 2003). Thereby, gamma activity during recognition of studied material has been associated with the reactivation of networks that have been established during prior encoding of the material. Moreover, in a recent source memory study, Gruber, Tsivilis, Giabbiconi, and Müller (2008) showed that gamma old/new effects can be functionally dissociated from theta $\mathrm{old} /$ new effects, suggesting that gamma and theta may be related to different memory processes. Consistently, in 


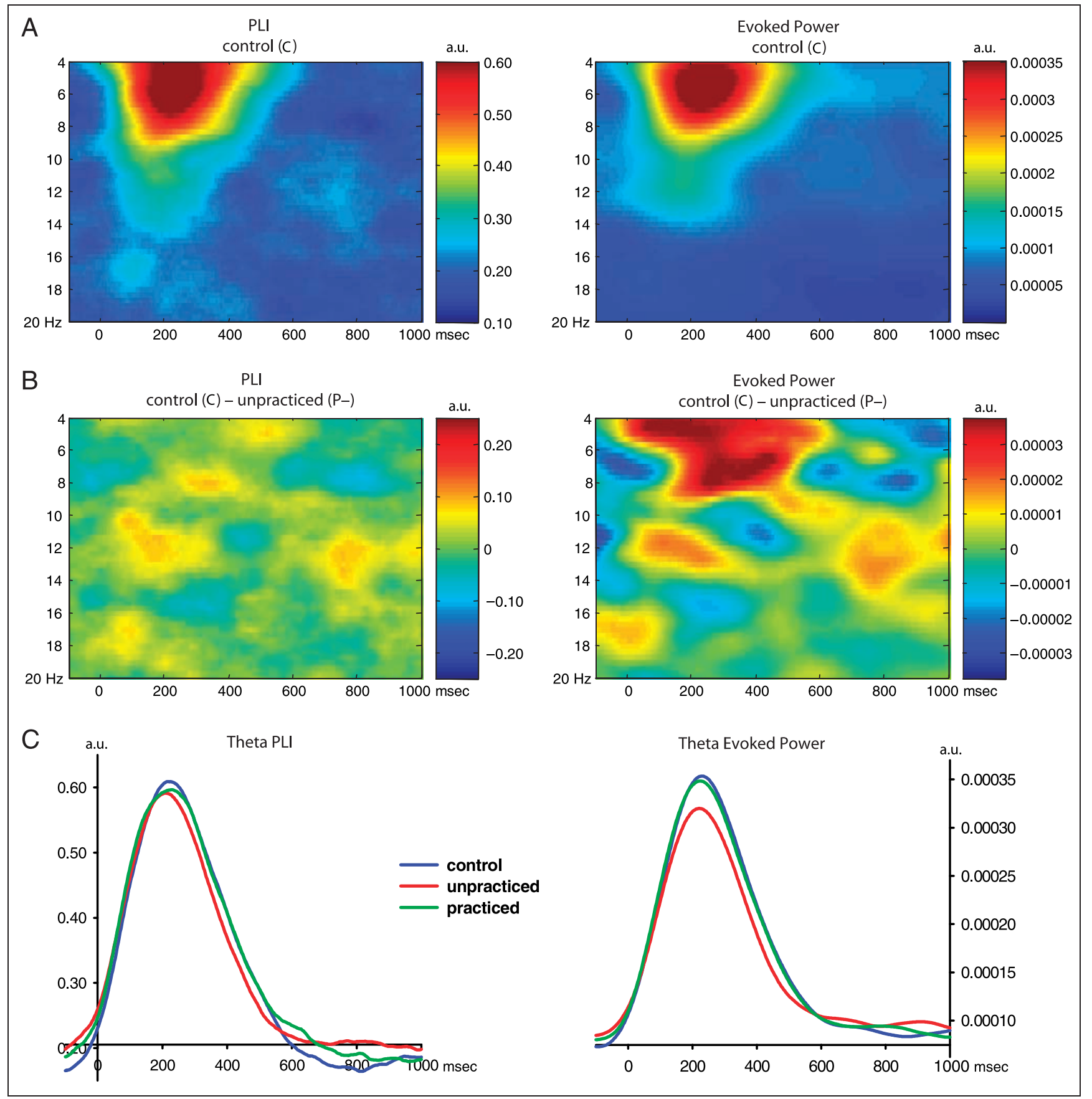

Figure 4. PLI and evoked power results. (A) PLI (left) and evoked power (right) at mid-frontal recording sites (MF) for correctly recognized control items. (B) PLI (left) and evoked power (right) difference plots for the forgetting contrast; (C) PLI (left) and evoked power (right) in the theta frequency range $(4-7 \mathrm{~Hz})$; line coding analogous to Figure $2 \mathrm{~A}$.

contrast to mid-frontal theta power, occipital gamma power did not show any difference between the highand the low-forgetting group in the present experiment, which may indicate that the reductions in gamma power and the reductions in theta power reflect different aspects of the inhibition effect on episodic memory. Given that occipital gamma activity has been closely linked to the integration of multiple sensory information into coherent object representations (e.g., Tallon-Baudry \& Bertrand, 1999), we argue that the present reduction in occipital gamma power during recognition of unpracticed material may, in particular, reflect a weakening of the material's sensory representation in memory.

\section{Effects on Alpha and Beta Power}

In addition to correlates of recognition memory in theta and gamma power reported above, the present analysis yielded old/new effects in the alpha and beta frequency range $(8-20 \mathrm{~Hz})$. In a comparatively late time window 
(>650 msec), hits were generally characterized by a significantly stronger alpha and beta power decrease compared to correct rejections. To date, only relatively few studies have reported late recognition old/new effects in this frequency range (e.g., Burgess \& Gruzelier, 2000). However, frontal ERP old/new effects have often been observed for similarly late time windows, albeit not in the present study. Such late frontal ERP old/new effects have been tentatively associated with postretrieval evaluation processes (for reviews, see Wilding \& Sharpe, 2003; Rugg \& Allan, 2000), whereas event-related power decreases of alpha oscillations have been associated with active cognitive processing and complex spreading activation processes (for a review, see Klimesch et al., 2007). We suggest that the alpha old/new effect in the present experiment reflects monitoring processes, which may be related to the repeated processing of the material in prior phases of the experiment. This interpretation is consistent with the finding that the alpha power decrease was selectively increased for practiced material and the increase was positively correlated with performance in the retrieval-practice phase. ${ }^{2}$ In contrast, the old/new effect in the beta frequency range was unaffected by the retrieval practice manipulation. Possibly, this effect reflects some sort of basal activation (e.g., activation of semantic networks). Further work is needed to examine these issues in more detail.

\section{ERP Effects of Retrieval Practice}

\section{Effects on the ERP P2 Component}

In addition to the reductions in theta and gamma power, recognition of unpracticed material was further associated with reduced amplitudes of the ERP P2 component. Frontal old/new effects in the time window of the P2 after visual presentation of studied words have been tentatively related to modality-specific implicit priming, but it remains unclear whether such early ERP effects may alternatively reflect explicit memory processes (e.g., Curran \& Dien, 2003). The view of retrieval-induced forgetting as a result of inhibition of the affected material's memory representation is compatible with either interpretation of $\mathrm{P} 2$ modulations in episodic recognition. Consistently, the detrimental effects of retrieval practice have been demonstrated not only in explicit but also in implicit memory tests (e.g., Bajo et al., 2006; Veling \& Van Knippenberg, 2004).

Frequency analysis suggests that the observed decrease in P2 amplitude was moderated by a reduction in theta power but not in theta phase locking, indicating that recognition of unpracticed material was associated with reduced neural activity in the theta frequency range. The conjecture of a possible relation between ERP P2 and early theta power is further supported by the observation that, in both measures, the reductions for unpracticed material were associated with decre- ments in actual recognition memory performance for these items. On balance, the analysis of P2 amplitudes and theta activity suggests that unpracticed items seem to have elicited only relatively weak early memory signals, which is in line with the proposal that the material's memory representation was inhibited.

\section{Effects on LPP and FN400}

Whereas the inhibitory mechanisms underlying retrievalinduced forgetting are assumed to directly affect an item's inherent representation, the strengthening of repeatedly processed material is typically attributed to an increase in association between the material and its cue(s) (e.g., Raaijmakers \& Shiffrin, 1981; Rundus, 1973). In particular, in the present experiment, the retrievalpractice phase allowed for associating the to-be-practiced material with a novel episodic context in addition to initial study. Consistently, recognition of practiced items was characterized by significantly stronger LPP. Indeed, a large body of literature has linked late parietal ERP old/ new effects with episodic recollection of spatio/temporal information associated with the prior occurrence of a recognized stimulus (for reviews, see Curran et al., 2006; Rugg \& Yonelinas, 2003; Mecklinger, 2000). The observed increase in late parietal ERP positivity may thus reflect the recollection of particularly rich episodic memories associated with the practiced material.

In the present study, we failed to replicate familiarityrelated mid-frontal ERP old/new effects in the FN400 time window. This failure may be attributable to particular methodological requirements of the retrieval-practice paradigm. There is evidence that a category's relatively strong items are susceptible to retrieval-induced forgetting but not a category's weak items (Bäuml, 1998; Anderson et al., 1994). Therefore, the word material we used in the present experiment consisted of quite typical (strong) and highly frequent category exemplars, which most likely were preexperimentally very familiar to the subjects. It has been shown that the N400 component, an ERP measure of semantic integration processes, is smaller for words with high typicality (e.g., Kutas \& Federmeier, 2000). In addition, a recent study showed that the magnitude of the N400 at study is positively correlated with the size of the mid-frontal old/new effect at test (Meyer, Mecklinger, \& Friederici, 2007). This suggests that the requisite use of highly typical material from common semantic categories that entails only few semantic integration processes might have generally alleviated mid-frontal old/new effects in the time window of the (F)N400. ${ }^{3}$

\section{Dissociable Oscillatory and ERP Correlates for Practiced and Unpracticed Material}

In this study, the detrimental and the beneficial effects of retrieval practice were qualitatively dissociable. None of the recognition memory correlates reflecting the 
weakening of the unpracticed material's memory traces (theta power, gamma power, P2 component) was increased for practiced material and none of the correlates reflecting the strengthening of practiced material (alpha power decrease, LPP component) was reduced for unpracticed material. These dissociations are consistent with a number of behavioral studies examining the effects of retrieval practice. They reported detrimental effects on the unpracticed material without enhancing effects on the practiced material (Gómez-Ariza, Lechuga, Pelegrina, \& Bajo, 2005; Veling \& Van Knippenberg, 2004), and beneficial effects on the practiced material without detrimental effects on the unpracticed material (strength independence; Bäuml \& Kuhbandner, 2007; Bäuml \& Hartinger, 2002; Anderson et al., 2000; Anderson \& McCulloch, 1999). Together, the behavioral and the EEG data indicate that the beneficial and detrimental effects of retrieval practice are mediated by different mechanisms, the forgetting being due to inhibition of the item's representation and the enhancement reflecting increased associations between the item and contextual information.

In sum, in a recent study, EEG correlates of inhibitory processes as they operate during retrieval practice were reported (Johansson et al., 2007). Early onsetting prefrontal ERP modulations were identified as the neural signature of competitor inhibition. ${ }^{4}$ The present study is the first study to report EEG correlates of the effects of such inhibitory processes on a later recognition test. Early onsetting modulations of frontal EEG activity distinguished inhibited material at test from noninhibited control material. In particular, recognition of inhibited material was characterized by reduced theta power, indicating that inhibited material triggers only relatively weak early memory signals, consistent with the view that inhibition leads to a deactivation of the affected material's memory representation (see Anderson, 2003). Such deactivation may also include a weakening of the material's sensory representation, as suggested from the analysis of oscillatory gamma power. The comparison between the detrimental effects and the beneficial effects of retrieval practice additionally showed that the two effects lead to qualitatively dissociable EEG correlates. This finding is consistent with prior behavioral work and suggests that the beneficial and the detrimental effects of retrieval practice are mediated by different mechanisms.

\section{Acknowledgments}

This research was supported by a grant from the German Research Foundation (DFG) to Karl-Heinz Bäuml, Bertram Opitz, and Axel Mecklinger (FOR 448). We thank V. Bauer, M. Gruber, P. Leipold, and R. Schmidtner for their help in the experimental work and the anonymous referees for their comments on a previous version of the manuscript.

Reprint requests should be sent to Karl-Heinz Bäuml, Department of Experimental Psychology, Regensburg University,
93040 Regensburg, Germany, or via e-mail: karl-heinz.baeuml@ psychologie.uni-regensburg.de.

\section{Notes}

1. The beta old/new effects reported here were also weakly present in slightly higher frequencies $(20-25 \mathrm{~Hz}$, not shown in Figure 3). We consider these effects to be residual projections of the reported beta old/new effects. Central to the present analysis, frequencies from 20 to $50 \mathrm{~Hz}$ exhibited no significant effects of retrieval practice status $(\mathrm{P}+, \mathrm{C}, \mathrm{P}-)$ and were thus omitted for reasons of clarity.

2. Across participants, the alpha power decrease for practiced $(\mathrm{P}+)$ compared to control material in the test phase was positively correlated with performance in the prior retrievalpractice phase [LP: $\left.r_{\mathrm{sp}}=.43, p<.05\right]$.

3. Another potential explanation for the lack of FN400 effects in the present study may be the practice of re-referencing the EEG data to a common average reference. However, in a preliminary ERP analysis in which we re-referenced the data to an off-line simulated linked mastoid reference, no FN400 effects were obtained. We therefore do not consider the lack of FN400 effects to be a result of the particular referencing method used in the present analysis.

4. For ERP analysis of the retrieval-practice phase, Johansson et al. (2007) contrasted a retrieval condition with a relearning baseline condition, in which the to-be-practiced material was re-exposed for additional study. Because the present study did not use this relearning baseline, it does not allow for a comparison with Johansson et al.'s results from the retrievalpractice phase.

\section{REFERENCES}

Anderson, M. C. (2003). Rethinking interference theory: Executive control and the mechanisms of forgetting. Journal of Memory and Language, 49, 415-445.

Anderson, M. C., Bjork, E. L., \& Bjork, R. A. (2000). Retrieval-induced forgetting: Evidence for a recall-specific mechanism. Psychonomic Bulletin E Review, 7, 522-530.

Anderson, M. C., Bjork, R. A., \& Bjork, E. L. (1994). Remembering can cause forgetting: Retrieval dynamics in long-term memory. Journal of Experimental Psychology: Learning, Memory, and Cognition, 20, 1063-1087.

Anderson, M. C., \& McCulloch, K. C. (1999). Integration as a general boundary condition on retrieval-induced forgetting. Journal of Experimental Psychology: Learning, Memory, and Cognition, 25, 608-629.

Anderson, M. C., Ochsner, K. N., Kuhl, B., Cooper, J., Robertson, E., Gabrieli, S. W., et al. (2004). Neural systems underlying the suppression of unwanted memories. Science, 30, 232-235.

Anderson, M. C., \& Spellman, B. A. (1995). On the status of inhibitory mechanisms in cognition: Memory retrieval as a model case. Psychological Review, 102, 68-100.

Aslan, A., Bäuml, K.-H., \& Pastötter, B. (2007). No inhibitory deficit in older adults' episodic memory. Psychological Science, 18, 72-78.

Bajo, M. T., Gómez-Ariza, C. J., Fernandez, A., \& Marful, A. (2006). Retrieval-induced forgetting in perceptually driven memory tests. Journal of Experimental Psychology: Learning, Memory, and Cognition, 32, 1185-1194.

Battig, W. F., \& Montague, W. E. (1969). Category norms of verbal items in 56 categories: A replication and extension of the Connecticut category norms. Journal of Experimental Psychology, 80, 1-64. 
Bäuml, K.-H. (1998). Strong items get suppressed, weak items do not: The role of item strength in output interference. Psychonomic Bulletin \& Review, 5, 459-463.

Bäuml, K.-H. (2002). Semantic recall can cause episodic forgetting. Psychological Science, 13, 356-360.

Bäuml, K.-H. (2008). Inhibitory processes. In H. L. Roediger, III (Ed.), Cognitive psychology of memory. Vol. 2 of Learning and memory: A comprehensive reference (pp. 195-220). Oxford: Elsevier.

Bäuml, K.-H., \& Hartinger, A. (2002). On the role of item similarity in retrieval-induced forgetting. Memory, 10, 215-224.

Bäuml, K.-H., \& Kuhbandner, C. (2007). Remembering can cause forgetting-But not in negative moods. Psychological Science, 18, 111-115.

Bäuml, K.-H., Zellner, M., \& Vilimek, R. (2005). When remembering causes forgetting: Retrieval-induced forgetting as recovery failure. Journal of Experimental Psychology: Learning, Memory, and Cognition, 31, 1221-1234.

Burgess, A. P., \& Gruzelier, J. H. (2000). Short duration power changes in the EEG during recognition memory for words and faces. Psychophysiology, 37, 596-606.

Camp, G., Pecher, D., \& Schmidt, H. G. (2007). No retrieval-induced forgetting using item-specific independent cues: Evidence against a general inhibitory account. Journal of Experimental Psychology: Learning, Memory, and Cognition, 33, 950-958.

Ciranni, M. A., \& Shimamura, A. P. (1999). Retrieval-induced forgetting in episodic memory. Journal of Experimental Psychology: Learning, Memory, and Cognition, 25, 1403-1414.

Curran, T. (1999). The electrophysiology of incidental and intentional retrieval: ERP old/new effects in lexical decision and recognition memory. Neuropsychologia, 37, 771-785.

Curran, T., \& Dien, J. (2003). Differentiating amodal familiarity from modality-specific memory processes: An ERP study. Psychophysiology, 40, 979-988.

Curran, T., Tepe, K. L., \& Piatt, C. (2006). ERP explorations of dual processes in recognition memory. In H. D. Zimmer, A. Mecklinger, \& U. Lindenberger (Eds.), Binding in buman memory: A neurocognitive approach (pp. 467-492). Oxford: Oxford University Press.

Düzel, E., Habib, R., Schott, B., Schoenfeld, A., Lobaugh, N., McIntosh, A. R., et al. (2003). A multivariate, spatiotemporal analysis of electromagnetic time-frequency data of recognition memory. Neuroimage, 18, 185-197.

Fell, J., Dietl, T., Grunwald, T., Kurthen, M., Klaver, P., Trautner, P., et al. (2004). Neural bases of cognitive ERPs: More than phase reset. Journal of Cognitive Neuroscience, 16, 1595-1604.

Gómez-Ariza, C. J., Lechuga, M. T., Pelegrina, S., \& Bajo, M. T. (2005). Retrieval-induced forgetting in recall and recognition of thematically related and unrelated sentences. Memory \& Cognition, 33, 1431-1441.

Gruber, T., Tsivilis, D., Giabbiconi, C. M., \& Müller, M. M. (2008). Induced electroencephalogram oscillations during source memory: Familiarity is reflected in the gamma band, recollection in the theta band. Journal of Cognitive Neuroscience, 20, 1043-1053.

Gruber, T., Tsivilis, D., Montaldi, D., \& Müller, M. M. (2004). Induced gamma band responses: An early marker of memory encoding and retrieval. NeuroReport, 15, 1837-1841.

Gruber, W., Klimesch, W., Sauseng, P., \& Doppelmayr, M. (2005). Alpha phase synchronization predicts P1 and N2 latency and amplitude size. Cerebral Cortex, 15, 271-277.

Hanslmayr, S., Klimesch, W., Sauseng, P., Gruber, W., Doppelmayr, M., Freunberger, R., et al. (2007). Alpha phase reset contributes to the generation of ERPs. Cerebral Cortex, 17, 1-8.

Herrmann, C. S., Munk, M. H. J., \& Engel, A. K. (2004). Cognitive functions of gamma-band activity: Memory match and utilization. Trends in Cognitive Sciences, 8, 347-355.

Hicks, J. L., \& Starns, J. (2004). Retrieval-induced forgetting occurs in tests of item recognition. Psychonomic Bulletin E Review, 11, 125-130.

Ille, N., Berg, P., \& Scherg, M. (2002). Artifact correction of the ongoing EEG using spatial filters based on artifact and brain signal topographies. Journal of Clinical Neurophysiology, 19, 113-124.

Jacobs, J., Hwang, G., Curran, T., \& Kahana, M. J. (2006). EEG Oscillations and recognition memory: Theta correlates of memory retrieval and decision making. Neuroimage, 32, 978-987.

Jäger, T., Mecklinger, A., \& Kipp, K. H. (2006). Intraand inter-item associations doubly dissociate the electrophysiological correlates of familiarity and recollection. Neuron, 52, 535-545.

Johansson, M., Aslan, A., Bäuml, K.-H., Gäbel, A., \& Mecklinger, A. (2007). When remembering causes forgetting: Electrophysiological correlates of retrieval-induced forgetting. Cerebral Cortex, 17, 1335-1341.

Kahana, J. (2006). The cognitive correlates of human brain oscillations. Journal of Neuroscience, 26, 1669-1672.

Klimesch, W., Doppelmayr, A., Yonelinas, A., Kroll, N. E. A., Lazzara, M., Röhm, D., et al. (2001). Theta synchronization during episodic retrieval: Neural correlates of conscious awareness. Cognitive Brain Research, 12, 33-38.

Klimesch, W., Hanslmayr, S., Sauseng, P., Gruber, W., Brozinsky, C. J., Kroll, N. E. A., et al. (2006). Oscillatory EEG correlates of episodic trace decay. Cerebral Cortex, 16, 280-290.

Klimesch, W., Sauseng, P., \& Hanslmayr, S. (2007). EEG alpha oscillations: The inhibition-timing hypothesis. Brain Research Reviews, 53, 63-88.

Klimesch, W., Schimke, H., \& Schwaiger, J. (1994). Episodic and semantic memory: An analysis in the EEG theta and alpha band. Electroencephalography and Clinical Neurophysiology, 91, 428-441.

Kuhl, B. A., Dudukovic, N. M., Kahn, I., \& Wagner, A. D. (2007). Decreased demands on cognitive control reveal the neural processing benefits of forgetting. Nature Neuroscience, 10, 908-914.

Kutas, M., \& Federmeier, K. D. (2000). Electrophysiology reveals semantic memory use in language comprehension. Trends in Cognitive Sciences, 4, 463-470.

Makeig, S., Westerfield, M., Jung, T. P., Enghoff, S., Townsed, J., Courchesne, E., et al. (2002). Dynamic brain sources of visual evoked responses. Science, 295, 690-694.

Mannhaupt, H.-R. (1983). Reproduktionsnormen für verbale Reaktionen zu 40 geläufigen Kategorien. Sprache und Kognition, 4, 264-278.

Mecklinger, A. (2000). Interfacing mind and brain: A neurocognitive model of recognition memory. Psychophysiology, 37, 565-582.

Meyer, P., Mecklinger, A., \& Friederici, A. D. (2007). Bridging the gap between the semantic N400 and the early old/new memory effect. NeuroReport, 18, 1009-1013.

Osipova, D., Takashima, A., Oostenveld, R., Fernandez, G., Mariy, E., \& Jensen, O. (2006). Theta and gamma oscillations predict encoding and retrieval of declarative memory. Journal of Neuroscience, 26, 7523-7531.

Perfect, T. J., Stark, L. J., Tree, J. J., Moulin, C. J. A., Ahmed, L., \& Hutter, R. (2004). Transfer appropriate forgetting: The cue-dependent nature of retrieval-induced forgetting. Journal of Memory and Language, 51, 399-417. 
Pfurtscheller, G., \& Aranibar, A. (1977). Event-related cortical desynchronization detected by power measurements of scalp EEG. Electroencephalography and Clinical Neurophysiology, 44, 307-316.

Raaijmakers, J. G. W., \& Shiffrin, R. M. (1981). Search of associative memory. Psychological Review, 88, 93-134.

Roehm, D., Schlesewsky, M., Bornkessel, I., Frisch, S., \& Haider, H. (2004). Fractionating language comprehension via frequency characteristics of the human EEG.

NeuroReport, 15, 409-412.

Rugg, M. D., \& Allan, K. (2000). Event-related potential studies of memory. In E. Tulving \& F. I. M. Craik (Eds.), Oxford handbook of memory (pp. 521-537). New York: Oxford University Press.

Rugg, M. D., \& Doyle, M. C. (1992). Event-related potentials and recognition memory for low- and high-frequency words. Journal of Cognitive Neuroscience, 5, 69-79.

Rugg, M. D., Mark, R. E., Walla, P., Schloerscheidt, A. M., Birch, C. S., \& Allan, K. (1998). Dissociation of the neural correlates of implicit and explicit memory. Nature, 392, $595-598$

Rugg, M. D., \& Yonelinas, A. P. (2003). Human recognition memory: A cognitive neuroscience perspective. Trends in Cognitive Sciences, 7, 313-319.

Rundus, D. (1973). Negative effects of using list items as recall cues. Journal of Verbal Learning and Verbal Behavior, 12, 43-50.

Spitzer, B., \& Bäuml, K.-H. (2007). Retrieval-induced forgetting in item recognition: Evidence for a reduction in general memory strength. Journal of Experimental Psychology: Learning, Memory, and Cognition, 33, 863-875.

Tallon-Baudry, C., \& Bertrand, O. (1999). Oscillatory gamma activity in humans and its role in object representation. Trends in Cognitive Sciences, 3, 151-162.

Tsivilis, D., Otten, L. J., \& Rugg, M. D. (2001). Context effects on the neural correlates of recognition memory: An electrophysiological study. Neuron, 31, 497-505.

Veling, H., \& Van Knippenberg, A. (2004). Remembering can cause inhibition: Retrieval-induced inhibition as cue independent process. Journal of Experimental Psychology: Learning, Memory, and Cognition, 30, 315-318.

Voss, J. L., \& Paller, K. A. (2006). Fluent conceptual processing and explicit memory for faces are electrophysiologically distinct. Journal of Neuroscience, 26, 926-933.

Wilding, E. L., \& Sharpe, H. (2003). Episodic memory encoding and retrieval: Recent insights from event-related potentials. In A. Zani \& A. M. Proverbio (Eds.), The cognitive electrophysiology of mind and brain (pp. 169-196). San Diego, CA: Academic Press.

Williams, C. C., \& Zacks, R. T. (2001). Is retrieval-induced forgetting an inhibitory process? American Journal of Psychology, 114, 329-354.

Wimber, M., Rutschmann, R.-M., Greenlee, M. W., \& Bäuml, K.-H. (2008). Retrieval from episodic memory: Neural mechanisms of interference resolution. Journal of Cognitive Neuroscience. http://www.mitpressjournals.org/doi/pdf/ 10.1162/jocn.2009.21043.

Woodruff, C. C., Hayama, H. R., \& Rugg, M. D. (2006). Electrophysiological dissociation of the neural correlates of recollection and familiarity. Brain Research, 1100, 125-135.

Yovel, G., \& Paller, K. A. (2004). The neural basis of the butcher-on-the-bus phenomenon: When a face seems familiar but is not remembered. Neuroimage, 21, 789-900. 